\title{
Um convite ao lugar da diferença no currículo de educação em direitos humanos
}

\author{
Invitation to the place of difference in the human \\ rights education curriculum
}

\author{
Hugo Heleno Camilo Costa \\ Professor, Faculdade e Programa de Pós-graduação em Educação/Universidade do Estado do Rio de Janeiro. \\ hugoguimel@yahoo.com.br
}

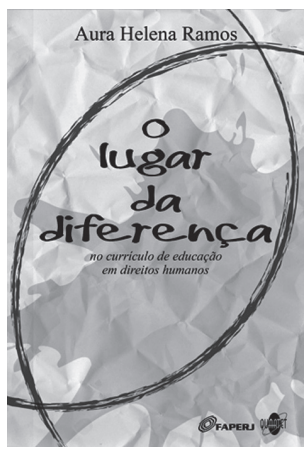

RAMOS, Aura Helena. Olugar da diferença no currículo de educação em direitos humanos. Rio de Janeiro: Quartet. 2011. $195 p$.
$\mathrm{I}_{\mathrm{n} i \mathrm{~m}}^{\mathrm{n}}$ nicio este texto com a ideia derridiana de disseminação. Para o filósofo franco-argelino (Derrida, 2001), a disseminação, diferentemente da polissemia, produz uma infinidade de sentidos, tornando impossível o acesso à origem do pensamento, do conhecimento. Essa concepção é um convite que a produção derridiana nos faz para pensar os desdobramentos generativos da interpretação, e é com essa deixa que, neste breve texto, convido à leitura do disseminador livro O lugar da diferença no currículo de educação em direitos humanos, de Aura Helena Ramos.

A dívida assumida ao ler/resenhar um livro é impagável e sempre uma injustiça, porque há, de praxe, traição interpretativa, violência para com discussões singulares e importantes, que são muitas ao longo do livro e que não cabem neste contexto. Defender uma vigilância na leitura/apresentação do texto, ou um melindre para com esta resenha, é, entretanto, tão importante quanto desnecessário, porque é impossível a precisão total, o controle absoluto sobre o entendimento do leitor deste texto, que já é uma supervisão. Dominar o pensamento da autora é a impossibilidade que nos cabe. Estar na interlocução, por meio da leitura do livro, é, de todas as maneiras, a possibilidade parcial que o papel de leitor viabiliza.

Meu convite se dá, então, na interpretação de que o livro em questão é um trabalho com potência para disseminar novos sentidos no âmbito das discussões sobre currículo para a Educação em Direitos Humanos (EDH) e, em seu dinamismo, instabilizar muitas questões que, frequentemente, tendem a ser supostas como fundamentais. Termos como o humano, diversidade, igualdade e direito, perdem, pelo trabalho de Aura Ramos, seu status de pressupostos e são submetidos à crítica pós-estrutural e pós-fundacional a partir de um olhar atento à diferença. 
Assumindo como problemática central a necessidade de uma reconceptualização do que se entende por "direitos humanos" e, especificamente, EDH, a autora se volta para a necessidade de operar uma densa discussão no campo em foco a partir dos estudos da diferença. Uma leitura de diferença como produção discursiva, produção cultural, como enunciação. Leitura que, articulada pela autora no campo discursivo da $\mathrm{EDH}$, lhe permite defender tais direitos como não estando fixados em seus sentidos, como não sendo objetos de conhecimento a difundir nas escolas, mas como produção diferencial escolar.

Para Ramos, mais importante e produtivo do que pensar a EDH de um ponto de vista normativo e de regulamentação da vida escolar, é operar com a leitura de que se constitui em experiência a ser construída, uma ética própria a ser performada, produzida, desenvolvida na relação com a diferença, com o outro. Isto é, assumir o conflito e a assimetria como meio de também enfatizar a dimensão política que caracteriza a vida social e oportuniza a circulação de sentidos provisórios.

Para a defesa de uma ética da diferença no currículo para a EDH, Aura Ramos empreende uma escavação nos pressupostos que dão base às discussões sobre o tema. A autora se volta para as construções discursivas nas políticas sobre EDH instalando um constrangimento no caráter de verdade última a que se pretendem as visões críticas e liberais, que colonizam as discussões sobre direitos humanos. Dessa forma, longe de pretender colaborar para a manutenção de tais verdades, assume um exercício de desconstrução dos discursos modernos, dos quais derivam diferentes visões a respeito desse tema.

Em seu trabalho de crítica ao embasamento moderno das discussões em torno dos direitos humanos, Ramos focaliza os discursos liberal e crítico, chamando a atenção para o fato de que, embora também se desenhem como críticas aos princípios e valores modernos e se oponham entre si, não deixam de operar no mesmo registro e de aspirar à condição de verdades inquestionáveis. Tais construções, segundo a autora, favorecem uma perspectiva violenta para com sua leitura de cultura e diferença, constituindo-se em críticas que tendem a suavizar o conflito, o dissenso, a relação com o outro, a produção cultural híbrida que compõe o currículo para a EDH.

Sem negligenciar um interessante diálogo sobre cultura e globalização, com autores como Vera Candau e Boaventura de Souza Santos, Ramos parte de uma afirmação radical da diferença, apoiando-se, para isso, nos estudos pós-críticos de Bhabha, Laclau e Mouffe. Com base nas perspectivas teóricas desses autores, vai focalizar o significante/nome vazio "direitos humanos" a partir das ideias de "universal" e "igualdade", que tendem a favorecer a subordinação do "outro", impondo-lhe o "mesmo" como condição para ser. Dito de outra forma, a autora busca pensar as ideias mencionadas em suas potencialidades de se constituir como padrões e verdades. E, como decorrência de tal construção universal, focaliza a tensão entre "igualdade" e "diferença" no âmbito escolar. Tensão que coloca a escola como lugar privilegiado para a socialização dos saberes elaborados, considerados universais, cuja finalidade seria a formação do cidadão, que, uma vez alcançada, levaria à igualdade social, à justiça social. É justamente na universalização de um modelo de cidadão, de humano, e, portanto, de educação, de valor, que se configura o alvo das críticas na obra de Ramos.

Em seu ritmo, a autora analisa os diferentes sentidos atribuídos à expressão "direitos humanos", chamando a atenção para o conflito em torno de sua significação. Para isso, 
retoma marcos das discussões de um contexto social mais amplo, atentando para questões como a globalização e a atuação da Organização das Nações Unidas (ONU), através da difusão da Declaração Universal dos Direitos Humanos, na tentativa de estabilização de uma visão universal de direitos humanos. Focaliza também, produções acadêmicas que tratam do tema, bem como lança mão de textos de entrevistas realizadas com lideranças nacionais que atuaram na produção de documentos de grande repercussão na definição de políticas de currículo para a EDH, tais como o Plano Nacional de Educação em Direitos Humanos (Brasil, 2003) e Subsídios para a elaboração das diretrizes gerais da Educação em Direitos Humanos (Dias, Nader, Silveira, 2007).

Tendo em vista tais documentos e pautada na teorização de Laclau e Mouffe, Aura Ramos propõe pensarmos as diferentes leituras que perpassam a denominação direitos humanos no cenário dos conflitos em prol da hegemonização de sentidos, de ideias. Conflitos que, para a autora, não devem ser entendidos nos termos de um "etapismo" histórico-social, mas como movimentos que, em cada contexto específico, produzem sentidos e fixam significados provisórios e contingentes. Com base nessa discussão, a autora pondera que não há um fechamento, ou significado, último em torno desse conflito, mas somente a produção de consensos conflituosos entre diferenças, entre diferentes demandas sociais.

Como via de acesso à parte de tais conflitos, ou consensos conflituosos, que marcam a produção das políticas de currículo para EDH, a autora chama a atenção para os processos de identificação e constituição dos grupos, compreendidos como elementos de uma comunidade política, que atuam no contexto de produção dos textos curriculares de EDH. A preocupação de Ramos, no que diz respeito aos fazeres de tais grupos, não está em destacar e culpar os atores envolvidos, mas em compreender as marcas de discursos, as tentativas de representação, que são provisoriamente constituídas nos documentos produzidos.

Trata-se, em sua opinião, de interpretar tais construções textuais para além de asserções objetivas, da superficialidade do que se coloca como pleito. Segundo Ramos, na abordagem aos textos da política, importa entendê-los como resultados contingentes das tensões entre distintos projetos envolvidos na política. Isso é conceber a produção da política como embate, negociação e hibridismo de sentidos, levando à hegemonização de verdades, presenças, ausências e silenciamentos.

Destaca-se, em termos de organização metodológica, a apropriação da teoria do ciclo de políticas de Stephen Ball, com vistas a pensar a produção da política como não detentora de uma gênese, um espaço originário, mas como uma produção textual discursiva contínua, que se dá no hibridismo de diferentes sentidos, no entrelaçamento de muitas verdades tramadas na política. Sentidos e verdades que circulam tanto em um cenário social mais amplo como naqueles que, em linhas gerais, se poderiam dizer mais restritos ou associados ao campo da educação.

Como resultado de seu trabalho de análise, Ramos propõe pensarmos "direitos humanos" como um significante vazio. Um significante, um nome, disputado em sua significação por diferentes grupos e que se desdobra para a/na escola com toda a sua rasurada significação, sendo ressignificado também na própria escola. A autora ressalta, como uma problemática, o desenvolvimento de tal conflito no campo discursivo da modernidade, no qual estão em confronto os discursos liberal e crítico, que se destacam em construções jurídico- 
políticas projetadas, marcadamente, por um viés universalista associado às perspectivas modernas.

Chama a atenção também para os deslizamentos de sentidos, no campo da corrente crítica, que tendem, na atualidade, a produzir sentidos híbridos, associados à discussão da diferença. O que, segundo a autora, tende a sustentar uma leitura de diferença nos termos da diversidade/pluralidade, cuja pretensão está na hegemonização das ideias de convivência multicultural e tolerância. A esse respeito, Ramos coloca sua crítica argumentando sobre a permanência da cultura como objeto de conhecimento, como repertório de sentidos a ser partilhados nas escolas.

Para Ramos, no âmbito das discussões sobre a $\mathrm{EDH}$, a saída via a tolerância mantém a estratégia moderna de universalização de valores particulares que nada mais são do que uma visão particular que, entre tantas outras, foi universalizada. Um universal que não é considerado verdade a ser ensinada nas escolas, algo capaz de suplantar, negligenciar ou minimizar, a diferença, o local. Justamente por não considerar tal pretensão universal como uma totalidade fixa, mas mantida por muitas articulações, a autora vai chamar a atenção, a partir de Mouffe e Bhabha, para o fato de que, além dos binarismos (liberal e crítico), o ímpeto discursivo colonial, ou seja, toda tentativa de colonização do outro, precisa negociar seu reconhecimento com a diferença, com o particular.

No entanto, apesar da consideração acima, a autora não supõe que a negociação com a diferença seja capaz de anestesiar os discursos modernos universalizados. Antes, chama a atenção para a importância de que sejam problematizadas, no âmbito do próprio discurso moderno, ideias como autonomia e diálogo, uma vez que tendem a ser pensadas a partir de decisões já tomadas, de verdades já estabelecidas. Portanto, "uma" autonomia e "um" diálogo controlados, circunscritos ao terreno das verdades modernas.

Para a autora, ainda é novo o campo de investigação em EDH e significativamente (ainda) pensado nos marcos da modernidade. Pensar os direitos humanos a partir da afirmação da diferença e não da universalidade de valores é o cerne do trabalho de Aura Ramos, desenhado como uma proposta de "abordagem agonística", expressão cunhada nas discussões de Chantal Mouffe e que supõe a negociação contínua com o outro. Uma proposta de "diálogo e consenso conflituosos" que, segundo a autora, reiteram a provisoriedade e contingência da política, da democracia. Um diálogo que não pretende estabelecer um último vencedor, mas favorecer políticas culturais que ampliem os espaços de negociação com a diferença, que preserve a interpretação do outro, que conceba a diferença como constitutiva e inerradicável do social.

Concluo pontuando o livro de Aura Ramos como uma grande contribuição à investigação em EDH. Argumento que a singularidade de sua produção consiste, também, no convite a um recuo estratégico na relação com o modo como são pensadas as justificativas, prioridades e metas para a educação em direitos humanos. Em seu trabalho investigativo, a autora provoca uma fratura no piso em que são assentadas as propostas no campo. Uma crítica severa aos significativos movimentos políticos/discursivos que tendem a assumir como problema os meios para a efetivação de ideais acertados pela modernidade, tanto por intermédio de perspectivas liberais, como críticas. O trabalho de Ramos vem de encontro à efervescência dos movimentos em prol da difusão de valores universais, tidos como absolutos e fundamentais ao social, à educação. Valores que, pretendidos à universalidade, tendem a ser incorporados 
ao campo da educação sem as devidas críticas e preocupações com a originalidade do local, da escola, da diferença. É na atenção para com essas dinâmicas que reside o convite da obra de Aura Ramos. Um convite a que desloquemos o olhar moderno sobre o humano e seus direitos (na educação), para pensar nos termos do direito humano à diferença.

\section{REFERÊNCIAS}

BRASIL.

Comitê Nacional de Educação em Direitos Humanos. Plano Nacional de Educação em Direitos Humanos. Brasília: Secretaria Especial dos Direitos Humanos, Ministério da Educação. 2003.

DERRIDA, Jacques.

Posições. Belo Horizonte: Autêntica. 2001.
DIAS, Adelaide A.; NADER, Alexandre Antônio Gili; SILVEIRA, Rosa M.G. (Org.).

Subsídios para a elaboração das diretrizes gerais da educação em direitos humanos: versão preliminar. João Pessoa: Editora Universitária UFPB. 2007.

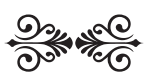

